\title{
Neoplasias espontâneas em camundongos de um centro de criação de animais de laboratório
}

\author{
[Spontaneous neoplasms in mice from a center of a laboratory animal breeding] \\ M.N.S. Trotte ${ }^{1}$, B.F. Santos ${ }^{2}$, R.C. Menezes ${ }^{3}$, R. Tortelly ${ }^{1}$ \\ ${ }^{1}$ Faculdade de Veterinária - UFF \\ Rua Vital Brazil Filho, 64 \\ 24230-340 - Niterói, RJ \\ ${ }^{2}$ Centro de Criação de Animais de Laboratório - FIOCRUZ - Rio de Janeiro, RJ \\ ${ }^{3}$ Instituto de Pesquisa Clínica Evandro Chagas - FIOCRUZ - Rio de Janeiro, RJ
}

\begin{abstract}
RESUMO
Verificaram-se a prevalência e as características anatomopatológicas de neoplasias espontâneas encontradas em camundongos, provenientes de biotério. Foram necropsiados 9.219 camundongos pertencentes a 13 linhagens, entre agosto de 2002 e janeiro de 2007, para monitoramento sanitário. Amostras de tecidos foram colhidas, fixadas em formol tamponado a $10 \%$ e processadas pelas técnicas habituais para inclusão em parafina. Foram realizados 84 diagnósticos de neoplasmas, sendo acometidos 82 camundongos $(0,9 \%)$. As principais neoplasias diagnosticadas com as respectivas ocorrências foram: carcinoma mamário, 27,4\%; linfoma, 19,0\%; adenocarcinoma papilífero pulmonar primário, 17,9\%; carcinoma epidermoide, $8,3 \%$; osteossarcoma osteoblástico, 4,8\%; e outros com menor porcentagem de ocorrência. Houve predomínio de tumores malignos, sendo mais frequentes os carcinomas mamários. A linhagem BALB/c An foi a que apresentou a maior variedade de tipos de neoplasias, seguida das linhagens outbred Swiss Webster e NIH. Fibrossarcoma em camundongos C57BL/10 ScSn-Dmd ${ }^{\mathrm{mdx}} / \mathrm{J}$ e carcinoma mamário na linhagem NOD foram relatados pela primeira vez.
\end{abstract}

Palavras-chave: Mus musculus, animal de laboratório, neoplasias, patologia

\begin{abstract}
The prevalence and the pathologic features of spontaneous neoplasms found in mice from a breeding colony were verified. Nine thousand two hundred and nineteen mice belonging to 13 strains were submitted to necropsy from August 2002 to January 2007 for health monitoring. Tissue samples were collected, fixed in $10 \%$ buffered formalin, and processed by the usual techniques for inclusion in paraffin. Eighty-four neoplasms were diagnosed and 82 mice had tumors (0.9\%). The main neoplasms were diagnosed with the following occurrences: mammary carcinoma, 27.4\%; lymphoma, 19.0\%; primary papillary pulmonary adenocarcinoma, 17.9\%; squamous carcinoma, 8.3\%; osteoblastic osteosarcoma, 4.8\%; and others with a lower percentage of occurrence. The malignant tumors predominated and the most common tumor was the mammary carcinoma. The wider variety of neoplasm types was found in the $B A L B / c$ An strain, followed by the outbred strains Swiss Webster and NIH. The fibrossarcoma in C57BL/10 ScSn-Dmd ${ }^{m d x} / J$ mice and mammary carcinoma in NOD mice were reported for the first time.
\end{abstract}

Keywords: Mus musculus, laboratory animal, neoplasms, pathology

Recebido em 20 de junho de 2009

Aceito em 30 de julho de 2010

E-mail: marceletrotte@vm.uff.br 


\section{INTRODUÇÃO}

Os camundongos têm sido utilizados como importantes modelos animais para pesquisas sobre a biologia e genética do câncer no homem, por cerca de um século. As linhagens mais utilizadas nesses estudos são as inbred ou consanguíneas, pois possuem recursos genéticos únicos para identificação de alelos ou locos de caracteres quantitativos que predispõem à oncogênese. Adicionalmente, as linhagens consanguíneas constituem matéria-prima para geração de camundongos geneticamente modificados, que se tornaram ferramentas imprescindíveis para pesquisas de neoplasias. Atualmente, há centenas de linhagens inbred que carreiam combinações distintas de genes alelos em um estado estável e variam grandemente nos diferentes tipos de tumores que desenvolvem (Näf et al., 2002).

O conhecimento sobre a frequência e fenótipos de neoplasias espontâneas inatas de uma linhagem particular de camundongo é de extrema importância para o desenvolvimento de novos modelos desses animais para a pesquisa do câncer, tanto na construção de uma nova linhagem mutante, como na escolha de linhagens para um estudo de caracteres complexos ou desenho de outros experimentos (Näf et al., 2002; Krupke et al., 2008). Devido à relevância dessas informações, um dos maiores laboratórios mundiais de produção e desenvolvimento de linhagens de camundongos, denominado "The Jackson Laboratory", nos EUA, criou uma grande base de dados eletrônica, publicamente acessível pela internet, sobre patologia, biologia e genética de neoplasias em modelos de camundongos para estudos dessas doenças no homem (Näf et al., 2002; Krupke et al., 2008). O estudo anatomopatológico dos tipos de neoplasias nesses animais é também importante para o diagnóstico diferencial com outras enfermidades de camundongos.

Entretanto, não há levantamento em biotérios brasileiros sobre a ocorrência de neoplasias espontâneas em camundongos. Portanto, a presente pesquisa teve por objetivo verificar a prevalência e as características anatomopatológicas de neoplasias espontâneas encontradas em camundongos, provenientes de biotério.

\section{MATERIAL E MÉTODOS}

No período de agosto de 2002 a janeiro de 2007, foram estudados 9.219 camundongos (Mus musculus) pertencentes às linhagens inbred $\mathrm{C} 3 \mathrm{H} / \mathrm{He}, \mathrm{C} 3 \mathrm{H} / \mathrm{He} \mathrm{J}, \mathrm{C} 57 \mathrm{BL} / 6, \mathrm{C} 57 \mathrm{BL} / 10$, BALB/c An, BALB/c-Lgals3, BALB/c-I14, B6. 129S6-Pfp, C57BL/10 ScSn-Dmd mdx/J, NOD, BP-2 -; e às linhagens outbred - Swiss Webster e NIH -, livres de germes patogênicos específicos (SPF) e convencionais, criados e mantidos no Centro de Criação de Animais de Laboratório (CECAL), FIOCRUZ, Rio de Janeiro, RJ.

Os animais foram mantidos em gaiolas de polipropileno, com cama de maravalha autoclavada e tampa de aço inox, em salas à temperatura de 21 a $24^{\circ} \mathrm{C}$, com 10 a 15 trocas de ar por hora, umidade de 45 a $55 \%$ e ciclo de luz de 12 horas. A água, autoclavada para os animais SPF ou filtrada para os convencionais, foi fornecida em bebedouros autoclavados e trocada a cada dois dias. A ração foi fornecida ad libitum e formulada para roedores. A Nuvital CR-1 ${ }^{\circledR}$ autoclavável foi fornecida aos animais SPF, e a Nuvital CR-1 ${ }^{\circledR}$ para os convencionais.

Os animais foram submetidos à eutanásia em câmara de gás carbônico e foram necropsiados para monitoramento sanitário no Departamento de Controle da Qualidade Animal do CECAL. Entre esses animais, 3.741 eram machos, 3.542 fêmeas e 1.936 sem informações sobre o sexo. Além disso, 3.323 deles eram adultos, com idade entre três e 18 meses, 694 jovens, com idade entre 21 dias e dois meses, e 5.202 sem idade informada.

Nas necropsias, amostras teciduais foram colhidas e imediatamente fixadas em solução de formol tamponado a $10 \%$. Posteriormente, os tecidos foram encaminhados ao Serviço de Anatomia Patológica Veterinária Professor Jefferson Andrade dos Santos, da Universidade Federal Fluminense, onde foram processados 
pelas técnicas habituais para inclusão em parafina e corados pela hematoxilina-eosina (HE). As lâminas de histopatologia foram analisadas em microscópico óptico (Olympus Bx 41), e as fotomicrografias foram obtidas a partir de uma câmera digital acoplada ao microscópio.

Os neoplasmas foram diagnosticados de acordo com a classificação histológica dos tumores nos animais, seguindo os critérios da Organização Mundial de Saúde (Slayter et al., 1994; Goldschmidt et al., 1998; Hendrick et al., 1998; Kennedy et al., 1998; Dungworth et al., 1999; Misdorp et al., 1999; Valli et al., 2002; Head et al., 2003; Meuten et al., 2004).

O desenvolvimento deste trabalho foi autorizado pelo Comitê de Ética para o Uso de Animais (CEUA/FIOCRUZ), por meio da aprovação do programa $\mathrm{n}^{\mathrm{o}} \mathrm{P} 0044-00$.

\section{RESULTADOS E DISCUSSÃO}

Oitenta e dois camundongos apresentaram neoplasias, representando prevalência de $0,9 \%$. Essa casuística é bastante inferior à relatada por Prejean et al. (1973), Rowlatt et al. (1976) e Ward et al. (1979), que encontraram prevalências de 26, 43 e 46\%, respectivamente. Vários fatores podem estar relacionados com o desenvolvimento de neoplasias, tais como: idade, linhagem, população estudada, período de estudo, localização geográfica e nutrição dos animais (Harkness e Wagner, 1993). O número de diagnósticos de neoplasmas foi maior (84) que o número de animais com neoplasma (82), em função de dois animais terem apresentado mais de um tumor simultaneamente.

As neoplasias diagnosticadas com as respectivas ocorrências foram: carcinoma mamário, 27,4\% (Fig. 1A, 1B); linfoma, 19,0\% (Fig. 1C, 1D); adenocarcinoma papilífero pulmonar primário, $17,9 \%$ (Fig. 1E, 1F); carcinoma epidermoide, 8,3\%; osteossarcoma osteoblástico, 4,8\%; adenocarcinoma de glândula salivar, 2,4\%; carcinoma de célula basal, 2,4\%; fibrossarcoma,
2,4\%; sarcoma histiocítico, 2,4\%; e adenoma mamário, carcinoma bronquíolo-alveolar primário, carcinoma renal tubular, carcinoma sebáceo, condrossarcoma, fibroma ossificante, hemangiossarcoma, mixoma, pilomatricoma maligno, teratoma benigno e teratoma ovariano maligno com $1,2 \%$ de ocorrência cada. Os carcinomas mamários encontrados foram do tipo tubular, 13; túbulo-papilar, 8; tubular mucinoso, 1 e sólido, 1 .

Os grupos de neoplasias encontradas, o número de animais acometidos e as respectivas frequências no total de 84 neoplasmas encontrados foram: neoplasias de glândulas mamárias, 24 (28,6\%); neoplasias do sistema hematopoiético e linfático, 18 (21,4\%); neoplasias do sistema respiratório, 16 (19,0\%); neoplasias epiteliais e melanocíticas da pele, 11 $(13,1 \%)$; neoplasias dos ossos e articulações, 6 (7,1\%); neoplasias mesenquimatosas da pele e tecidos moles, 4 (4,8\%); neoplasias do sistema digestivo, 2 (2,4\%); neoplasias do sistema genital, 2 (2,4\%); neoplasias do sistema urinário, $1(1,2 \%)$.

Dos animais com neoplasias, todos eram adultos e apenas três animais não possuíam a idade informada. Quanto à classificação sanitária, dos animais com tumores, 60 eram convencionais, 20 SPF e dois não tinham informação sobre a classificação sanitária. A ocorrência de neoplasias foi maior em fêmeas, 73,2\%, semelhante ao já verificado por Prejean et al. (1973) e Haines et al. (2001) e diferente dos resultados de Rowlatt et al. (1976) e Ward et al. (1979). O elevado número de camundongos estudados sem informação sobre o sexo pode ter contribuído para o predomínio de machos ou fêmeas, com possível influência na prevalência total e nos tipos das neoplasias encontrados. Entretanto, em apenas quatro camundongos com neoplasias não havia informação sobre o sexo, o que não influenciou no maior número de neoplasias em fêmeas e na ordem de ocorrência dos tipos de neoplasias por sexo. 


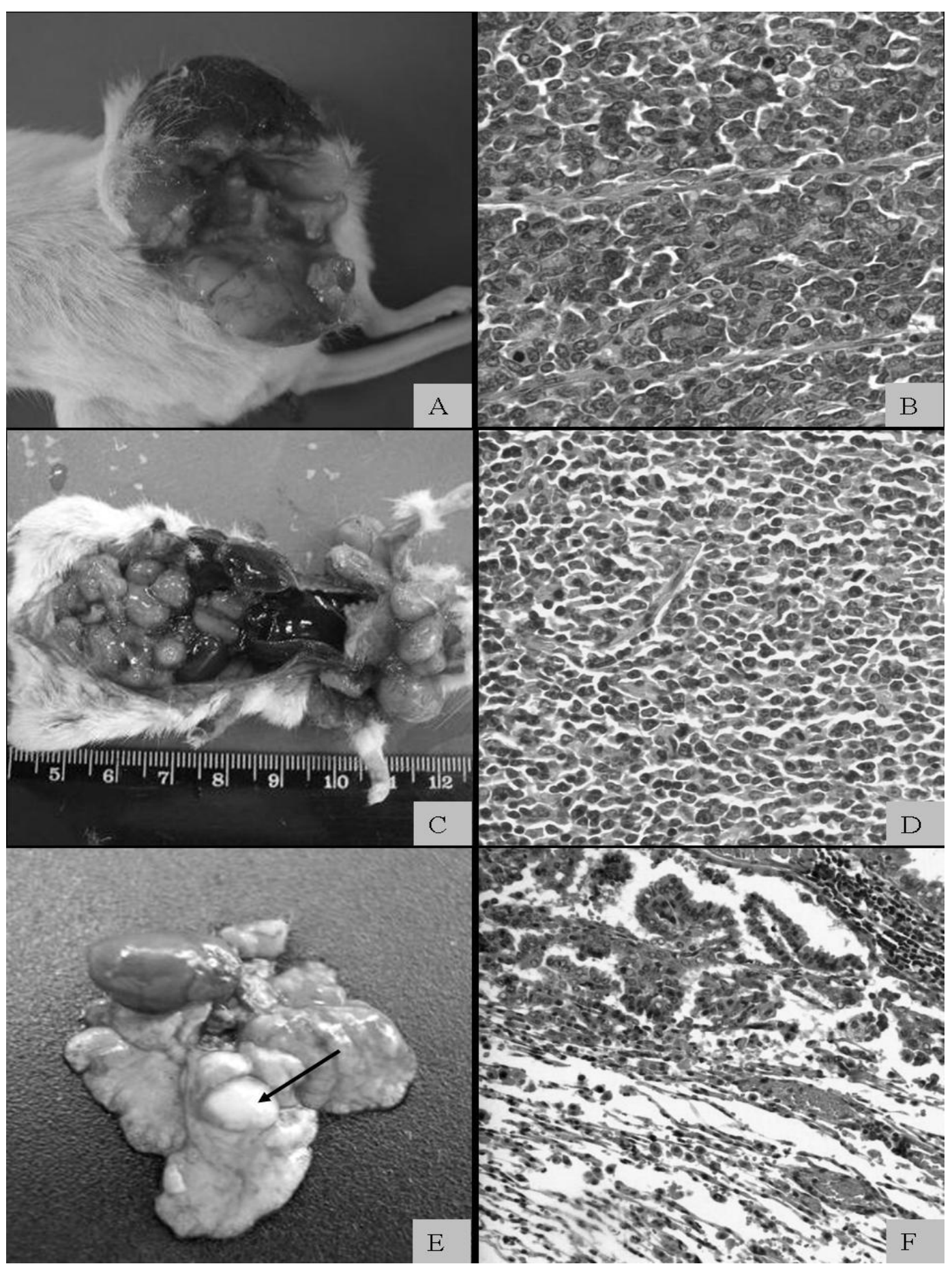

Figura 1. A) Camundongo NOD adulto fêmea. Glândula mamária. Massa tumoral brancacenta de superfície irregular, firme e medindo cerca de $3 \mathrm{~cm}$ de diâmetro. B) Camundongo $\mathrm{C} 3 \mathrm{H} / \mathrm{He}$ adulto fêmea. Glândula mamária. Carcinoma tubular. Túbulos formados por células neoplásicas pleomórficas. HE. C) Camundongo NIH adulto fêmea. Linfonodos e baço. Aumento do tamanho do baço e dos linfonodos mandibulares e axilares. D) Camundongo C57BL/10 adulto macho. Linfonodo. Linfoma. Células linfocíticas pleomórficas. HE. E) Camundongo BALB/c An adulto. Pulmão direito (lobo caudal). Nódulo branco subpleural de cerca de $3 \mathrm{~mm}$ de diâmetro (seta). F) Camundongo BALB/c An adulto macho. Pulmão. Adenocarcinoma papilífero. Área de transição entre o tecido pulmonar normal e área formada por células epiteliais colunares neoplásicas apresentando arranjos papilíferos. HE. (B e D: 400X, F: 200X). 
Nas fêmeas, o carcinoma mamário foi a neoplasia mais frequente e, nos machos, o adenocarcinoma papilífero pulmonar primário, diferente dos achados de Rowlatt et al. (1976) e Haines et al. (2001), nos quais os tumores de maior ocorrência foram o sarcoma histiocítico e o linfoma em ambos os sexos, respectivamente, em cada estudo. Neste estudo, os tumores malignos foram mais prevalentes, 95,2\%, sendo os carcinomas mamários os de maior ocorrência, 27,4\%. Esses resultados diferem dos encontrados por Prejean et al. (1973), Rabstein e Peters (1973), Ward et al. (1979) e Haines et al. (2001), em cujas pesquisas, respectivamente, os tumores de maior ocorrência foram o adenocarcinoma pulmonar, 30\%, carcinoma renal, 60-70\%, sarcoma histiocítico, 29,4\% e linfoma, 54,5\%.

As prevalências das neoplasias (animais acometidos/necropsiados) encontradas em cada linhagem de camundongo foram: 9,0\% (1/11) em BALB/c-Lgals3; 7,1\% (1/14) em BP2; 5,7\% (2/35) em C3H/HeJ; 3,8\% (1/26) em C57BL/10 ScSn-Dmd ${ }^{\mathrm{mdx}} / \mathrm{J} ; 2,1 \%$ (4/194) em B6.129S6Pfp; $1,6 \%$ (25/1.574) em BALB/c An; $1,3 \%$ (8/639) em C3H/He; 0,8\%(6/728) em NIH; 0,6\% (29/4.724) em Swiss Webster; 0,5\% (1/187) em BALB/c -IL4r; 0,5\% (2/409) em NOD; $0,4 \%(1 / 285)$ em C57BL/10;0,2\% (1/420) em C57BL/6. A distribuição dos tipos de neoplasias por linhagens e sexo de camundongos encontrase na Tab. 1.

Em relação à ocorrência de tipos de neoplasmas entre as diferentes linhagens, os camundongos $\mathrm{BALB} / \mathrm{c}$ An foram os que apresentaram a maior variedade, 12, e em diferentes tecidos, sendo mais frequentes os tumores pulmonares, mamários e o linfoma. Estes resultados estão de acordo com os relatados por outros autores (Deringer, 1965; Festing, 1996; The Jackson Laboratory, 2009), porém os tumores renais considerados de alta frequência nessa linhagem
(Staats, 1985) foram somente observados em um animal.

As linhagens $\mathrm{C} 3 \mathrm{H} / \mathrm{He}$ e $\mathrm{C} 3 \mathrm{H} / \mathrm{HeJ}$ apresentaram maior ocorrência de tumores mamários, semelhante à literatura, que relata alta ocorrência desses tipos de tumores nessas linhagens (Hoag, 1963). Todavia, tumores hepáticos, considerados de alta frequência nessas linhagens (Frith e Wiley, 1982), não foram encontrados.

Os linfomas são considerados de moderada frequência em C57BL/10 (Festing, 1996), sendo o osteossarcoma de alta ocorrência (Wadsworth, 1989). Na presente pesquisa, foram somente observados linfomas e em frequência inferior.

A ocorrência de linfoma na linhagem C57BL/6 no presente estudo é comumente relatada na literatura (Blackwell et al., 1995; The Jackson Laboratory, 2009). Entretanto, tumores de glândula pituitária, relatados como de ocorrência muito elevada (Staats, 1985), não foram observados.

Dentre as escassas neoplasias já relatadas na linhagem NOD, estão o osteossarcoma, também encontrado no presente estudo, mioepitelioma e adenocarcinoma das ilhotas de Langerhans (Festing, 1996; The Jackson Laboratory, 2009). Portanto, o carcinoma mamário foi relatado pela primeira vez.

O tumor mais comumente observado nos camundongos C57BL/10-Dmd ${ }^{\mathrm{mdx}} / \mathrm{J}$ é o rabsomiossarcoma (Chamberlain et al., 2007), sendo que o fibrossarcoma não havia sido citado para essa linhagem.

Segundo Prejean et al. (1973), o adenocarcinoma e o adenoma pulmonares são aos neoplasmas mais comuns em camundongos Swiss Webster, diferente desta pesquisa, na qual o linfoma foi o tumor de maior ocorrência. 
Tabela 1. Distribuição dos tipos de neoplasias por linhagens, sexo e idade dos camundongos provenientes de biotério ${ }^{1}$, verificados no período de agosto de 2002 a janeiro de 2007

\begin{tabular}{|c|c|c|c|c|c|}
\hline \multirow[t]{2}{*}{ Linhagem } & \multirow[t]{2}{*}{ Tipos de neoplasia } & \multirow[b]{2}{*}{$\mathrm{P}$} & \multicolumn{3}{|c|}{ Sexo } \\
\hline & & & M & $\mathrm{F}$ & $\mathrm{D}$ \\
\hline BALB/c-Lgals3 & Adenocarcinoma de glândula salivar & 1 & 1 & 0 & 0 \\
\hline BP2 & Carcinoma epidermoide & 1 & 0 & 1 & 0 \\
\hline $\mathrm{C} 3 \mathrm{H} / \mathrm{HeJ}$ & Carcinoma mamário & 2 & 0 & 2 & 0 \\
\hline C57BL/10 ScSn-Dmd ${ }^{\mathrm{mdx}} / \mathrm{J}$ & Fibrossarcoma & 1 & 0 & 1 & 0 \\
\hline \multirow[t]{3}{*}{ B6. 129S6-Pfp } & Linfoma & 2 & 2 & 0 & 0 \\
\hline & Carcinoma epidermoide & 1 & 0 & 1 & 0 \\
\hline & Fibrossarcoma & 1 & 0 & 1 & 0 \\
\hline \multirow[t]{12}{*}{ BALB/c An } & Adenocarcinoma papilífero pulmonar ${ }^{+}$ & 8 & 5 & 2 & 1 \\
\hline & Carcinoma mamário & 5 & 1 & 4 & 0 \\
\hline & Linfoma & 3 & 1 & 2 & 0 \\
\hline & Carcinoma bronquíolo-alveolar $^{+}$ & 1 & 0 & 0 & 1 \\
\hline & Carcinoma de célula basal & 1 & 0 & 1 & 0 \\
\hline & Carcinoma epidermoide & 1 & 0 & 1 & 0 \\
\hline & Carcinoma sebáceo & 1 & 0 & 1 & 0 \\
\hline & Pilomatricoma maligno & 1 & 0 & 1 & 0 \\
\hline & Osteossarcoma osteoblástico & 1 & 0 & 1 & 0 \\
\hline & Fibroma ossificante & 1 & 0 & 1 & 0 \\
\hline & Adenocarcinoma de glândula salivar & 1 & 0 & 1 & 0 \\
\hline & Carcinoma tubular renal $^{+}$ & 1 & 0 & 1 & 0 \\
\hline \multirow[t]{2}{*}{$\mathrm{C} 3 \mathrm{H} / \mathrm{He}$} & Carcinoma mamário tubular & 7 & 0 & 7 & 0 \\
\hline & Hemagiossarcoma & 1 & 1 & 0 & 0 \\
\hline $\mathrm{BALB} / \mathrm{c}-\mathrm{IL} 4 \mathrm{r}$ & Carcinoma epidermoide & 1 & 0 & 1 & 0 \\
\hline \multirow[t]{2}{*}{ NOD } & Carcinoma mamário & 1 & 0 & 1 & 0 \\
\hline & Osteossarcoma osteoblástico & 1 & 0 & 1 & 0 \\
\hline C57BL/10 & Linfoma & 1 & 1 & 0 & 0 \\
\hline C57BL/6 & Linfoma & 1 & 0 & 1 & 0 \\
\hline \multirow[t]{7}{*}{$\mathrm{NIH}$} & Adenoma mamário* & 1 & 0 & 1 & 0 \\
\hline & Carcinoma mamário & 1 & 0 & 1 & 0 \\
\hline & Adenocarcinoma papilífero pulmonar & 1 & 0 & 1 & 0 \\
\hline & Carcinoma de célula basal & 1 & 0 & 1 & 0 \\
\hline & Linfoma* & 1 & 0 & 1 & 0 \\
\hline & Osteossarcoma osteoblástico & 1 & 0 & 1 & 0 \\
\hline & Teratoma ovariano maligno & 1 & 0 & 1 & 0 \\
\hline \multirow[t]{9}{*}{ Swiss Webster } & Linfoma* & 8 & 3 & 4 & 1 \\
\hline & Carcinoma mamário & 7 & 0 & 7 & 0 \\
\hline & Adenocarcinoma papilífero pulmonar* ${ }^{+}$ & 6 & 3 & 2 & 1 \\
\hline & Carcinoma epidermoide & 3 & 0 & 3 & 0 \\
\hline & Sarcoma histiocítico & 2 & 0 & 2 & 0 \\
\hline & Condrossarcoma & 1 & 0 & 1 & 0 \\
\hline & Osteossarcoma osteoblástico & 1 & 0 & 1 & 0 \\
\hline & Mixoma & 1 & 1 & 0 & 0 \\
\hline & Teratoma benigno & 1 & 0 & 1 & 0 \\
\hline
\end{tabular}

P: número de neoplasias; M: machos; F: fêmeas; D: sexo desconhecido. *Nestas linhagens, um animal apresentou dois tipos de neoplasias. ${ }^{+}$Neoplasias primárias. ${ }^{1}$ Centro de Criação de Animais de Laboratório, FIOCRUZ, Rio de Janeiro, RJ. 
Nas neoplasias de glândulas mamárias, foram observadas massas tumorais com superfície irregular, que variavam entre 1 e $5 \mathrm{~cm}$ de diâmetro. Ao corte, eram consistentes e róseas ou brancacentas (Fig. 1A). Quanto à localização, estavam presentes nas regiões das glândulas mamárias torácicas e abdominais. As alterações macroscópicas e microscópicas foram similares às descritas por Garcia-Iglesias et al. (1997) em camundongos. Todavia, os carcinomas túbulopapilar e tubular mucinoso não foram citados por esses autores. Nielsen et al. (1991), assim como a presente pesquisa, também descreveram ocorrência de carcinoma mamário em machos. A susceptibilidade genética, o estímulo hormonal e o vírus do tumor mamário do camundongo ou vírus Bittner são os três principais fatores para o desenvolvimento, a incidência e o tipo histológico de tumor mamário em camundongos (Tsubura et al., 2007). Na presente pesquisa, $41,7 \%$ dos animais com esta neoplasia eram SPF, afastando a possibilidade de etiologia viral nestes roedores.

No grupo das neoplasias do sistema hematopoiético e linfático, os achados macroscópicos no linfoma (Fig. 1C) e no sarcoma histiocítico foram: baço aumentado cerca de três a 10 vezes o seu tamanho normal, com bordas arredondadas e manchas brancas na sua superfície, e linfonodos mandibulares, mediastínicos, axilares e mesentéricos aumentados cerca de quatro a seis vezes o seu tamanho normal.

Nos casos diagnosticados como neoplasias primárias pulmonares, havia nódulos múltiplos endurecidos, esbranquiçados ou rosados, e medindo entre 1 e $5 \mathrm{~mm}$ de diâmetro (Fig. 1E) na região subpleural e parênquima dos pulmões.

Em relação ao grupo de neoplasias epiteliais e melanocíticas da pele, os animais com carcinoma epidermoide apresentaram massa ulcerada na pele e no tecido subcutâneo, variando de 2 a $5 \mathrm{~cm}$ de diâmetro, localizada nas regiões do tórax e do abdômen. Ao corte, apresentava-se friável e com múltiplas e extensas áreas esbranquiçadas. Dois animais com metástase pulmonar e um com metástase hepática apresentavam nódulos nestes órgãos com o mesmo aspecto da neoplasia primária. Segundo Nielsen (1978), além dos carcinógenos químicos, como fuligem, e físicos, como radiação ultravioleta, a irritação crônica resultando em não cicatrização de úlceras e fístulas - também pode levar ao desenvolvimento do tumor. Nos animais com carcinoma de célula basal, foi observada massa solitária de superfície lobulada, localizada na pele e no tecido subcutâneo da região torácica, com cerca de $4 \mathrm{~cm}$ de diâmetro. Ao corte, era firme e rosada. O camundongo com pilomatricoma maligno apresentava massa de cerca de $1 \mathrm{~cm}$ de diâmetro, localizada na pele e no tecido subcutâneo da região torácica que foi diagnosticado como processo neoplásico folicular com presença de lóbulos de células basofílicas na periferia, e mais centralmente havia células fantasmas e queratinização. Gat et al. (1998) relataram alterações histopatológicas do pilomatricoma com característica benigna em camundongos, mas neste estudo este teve comportamento maligno, com presença de células pleomórficas e áreas de necrose de coagulação, semelhante ao descrito nos animais domésticos por Goldschmidt et al. (1998). O animal com carcinoma sebáceo apresentava massa de superfície lobulada na pele e tecido subcutâneo da região abdominal, medindo $2 \mathrm{~cm}$ de diâmetro, com consistência firme e esbranquiçado.

A alteração macroscópica do fibroma ossificante foi uma tumoração de cerca de $1 \mathrm{~cm}$ de diâmetro, aderida à órbita ocular direita. Ao corte, era firme e branco-amarelado, e foi caracterizado como um processo neoplásico benigno, com proliferação de fibroblastos e áreas de metaplasia óssea. No osteossarcoma osteoblástico foram observadas massas variando de 0,5 a $2 \mathrm{~cm}$ de diâmetro, aderidas à face (lado esquerdo), cabeça, cauda e parede da cavidade torácica. Ao corte, eram rosadas e rígidas. Nos dois animais com metástase pulmonar e um com metástase hepática, foram observados nódulos com o mesmo aspecto. $\mathrm{O}$ animal com condrossarcoma apresentou massa de cerca de $2 \mathrm{~cm}$ de diâmetro aderida ao membro posterior esquerdo (articulação fêmur-tibial), consistente e esbranquiçada. Wadsworth (1989) relatou casos 
de metástases pulmonar e hepática do osteossarcoma.

Um animal com fibrossarcoma apresentava massa de cerca de $4 \mathrm{~cm}$ de diâmetro na região láteroventral do tórax (lado esquerdo) aderida à musculatura, baço e fígado com nódulos esbranquiçados de cerca de $3 \mathrm{~mm}$ de diâmetro; um outro animal apresentou massa aderida à porção proximal do membro posterior direito, de cerca de $3 \mathrm{~cm}$ de diâmetro. Ao corte, eram firmes e róseas em ambos os casos. Na pesquisa de Machado et al. (1977), foi encontrado um caso de fibrossarcoma em camundongo na região abdominal, sem ocorrência de metástase. A alteração macroscópica do mixoma foi a presença de massa de cerca de $3 \mathrm{~cm}$ de diâmetro, localizada na pele e no tecido subcutâneo do membro anterior esquerdo, e consistente esbranquiçada. $\mathrm{O}$ camundongo com hemangiossarcoma apresentava massa de cerca de $2 \mathrm{~cm}$ de diâmetro localizada na pele e no tecido subcutâneo da região submandibular. Ao corte, era avermelhada e firme. Entretanto, Booth e Sundberg (1995) encontraram maior ocorrência de hemangiossarcoma em camundongos na região cutânea da cauda, enquanto no cão, baço, fígado, aurícula direita e pulmões foram os locais mais acometidos (Hendrick et al., 1998).

Nos dois animais com carcinoma de glândula salivar submandibular, foram observadas uma massa de $0,5 \mathrm{~cm}$ de diâmetro em um caso e duas massas de cerca de $2 \mathrm{~cm}$ de diâmetro no outro, todas localizadas na glândula salivar submandibular. Essas massas eram de superfície lobulada e vermelho-escuras. Nielsen et al. (1991), contudo, relataram ocorrência de metástases pulmonares desta neoplasia em camundongos, o que não ocorreu no presente estudo.

O camundongo com teratoma ovariano maligno apresentou baço e fígado com nódulos de cerca de $2 \mathrm{~mm}$ de diâmetro em sua superfície, marromclaros, e tumoração nodular no interior da cavidade abdominal de cerca de $8 \mathrm{~mm}$ de diâmetro, firme e vermelho-escura. No exame histológico, havia epitélio glandular, revestimento epitelial do trato respiratório, ninhos de células epiteliais escamosas com queratina, tecido ósseo e cartilagem bem diferenciados, área de necrose de coagulação e folículos ovarianos. No animal com teratoma benigno, a tumoração localizava-se na pele e no tecido subcutâneo, caudalmente ao pavilhão auricular esquerdo, com aproximadamente $2 \mathrm{~cm}$ de diâmetro, e era róseo-clara. Phillips e Hulse (1982) relataram dois casos de teratomas extragonadais em camundongos, com localização cutânea na região abdominal e na cauda. Macroscopicamente, esses autores descreveram o tumor com uma parte cística, diferente do observado no presente estudo. Mas, nos achados histopatológicos, havia também tecidos de origem dos três folhetos embrionários (ectoderma, endoderma e mesoderma) com características benignas. Um desvio na migração das células germinativas que iriam para as cristas genitais pode explicar a ocorrência de teratoma extragonadal (Phillips e Hulse, 1982). Abbott et al. (1983) relataram três casos de teratoma ovariano em camundongos, com características macroscópicas similares ao deste estudo. Todavia, nos achados histopatológicos desses autores, não houve metástases e áreas de necrose de coagulação.

No caso do carcinoma renal, foi observada uma massa atingindo o córtex do rim esquerdo, rósea e com cerca de $2 \mathrm{~cm}$ de diâmetro.

\section{CONCLUSÕES}

A prevalência de neoplasias espontâneas foi mais baixa que a encontrada em estudos similares, com predomínio de tumores malignos, sendo mais frequentes os carcinomas mamários. A linhagem BALB/c An foi a que apresentou a maior variedade de tipos de neoplasias, seguida das linhagens outbred Swiss Webster e NIH. Fibrossarcoma em camundongos C57BL/10 ScSn-Dmd ${ }^{\mathrm{mdx}} / \mathrm{J}$ e carcinoma mamário na linhagem NOD foram relatados pela primeira vez. 


\section{REFERÊNCIAS BIBLIOGRÁFICAS}

ABBOTT, D.P.; GREGSON, R.L.; IMM, S. Spontaneous ovarian teratomas in laboratory mice. J. Comp. Pathol., v.93, p.109-114, 1983.

BLACKWELL, B.N.; BUCCI, T.J.; HART, R.W. et al. Longevity, body weight, and neoplasia in ad libitum-fed and diet-restricted C57BL6 mice fed NIH-31 open formula diet. Toxicol. Pathol., v.23, p.570-582, 1995.

BOOTH, C.J.; SUNDBERG, J.P. Hemangiomas and hemangiosarcomas in inbred laboratory mice. Lab. Anim. Sci., v.45, p.497-502, 1995.

CHAMBERLAIN, J.S.; METZGER, J.; REYES, $M$. et al. Dystrophin-deficient mdx mice display a reduced life span and are susceptible to spontaneous rhabdomyosarcoma. FASEB J., v.21, p.2195-2204, 2007.

DERINGER, M.K. Occurrence of mammary tumors, reticular neoplasms, and pulmonary tumors in strain BALB-cAnDe breeding female mice. J. Natl. Cancer, v.35, p.1047-1052, 1965.

DUNGWORTH, D.L.; HAUSER, B.; HAHN, F.F. et al. World Health Organization. Histological classification of tumors of the respiratory system of domestic animals. 2 ed. Washington: Armed Forces Institute of Pathology and American Registry of Pathology, 1999. 70p.

FESTING, M.F.W. Inbred strains of mice (Updated July 30, 1996). Mouse Genome, v.94, p.523-677, 1996.

FRITH, C.H.; WILEY, L. Spontaneous hepatocellular neoplasms and hepatic hemangiosarcomas in several strains of mice. Lab. Anim. Sci., v.32, p.157-162, 1982.

GARCIA-IGLESIAS, M.J.; PEREZMARTINEZ, C.; BRAVO-MORAL, A. et al. A. Spontaneous mouse mammary tumours: incidence and cytokeratin expression. Res. Vet. Sci., v.63, p.85-89, 1997.

GAT, U.; DASGUPTA, R.; DEGENSTEIN, L. et al. De novo hair follicle morphogenesis and hair tumors in mice expressing a truncated $\beta$ catenin in skin. Cell, v.95, p.605-614, 1998.
GOLDSCHMIDT, M.H.; DUNSTAN, R.W.; STANNARD, A.A. et al. World Health Organization. Histological classification of epithelial and melanocytic tumors of the skin of domestic animals. 2.ed. Washington: Armed Forces Institute of Pathology and American Registry of Pathology, 1998. 105p.

HAINES, D.C.; CHATTOPADHYAY, S.; WARD, J.M. Pathology of aging B6;129 Mice. Toxicol. Pathol., v.29, p.653-661, 2001.

HARKNESS, J.E.; WAGNER, J.E. Biologia $e$ clínica de coelhos e roedores. 3.ed. São Paulo: Roca, 1993. 238p.

HEAD, K.W.; CULLEN, J.M.; DUBIELZIG, R.R. et al. World Health Organization. Histological classification of tumors of the alimentary system of domestic animals. 2.ed. Washington: Armed Forces Institute of Pathology and American Registry of Pathology, 2003. 257p.

HENDRICK, M.J.; MAHAFFEY E.A.; MOORE, F.M. et al. World Health Organization. Histological classification of mesenchymal tumors of skin and soft tissues of domestic animals. 2.ed. Washington: Armed Forces Institute of Pathology and American registry of Pathology, 1998. 62p.

HOAG, W.G. Spontaneous cancer in mice. Ann. N. Y. Acad. Sci., v.108, p.805-831, 1963.

KENNEDY, P.C.; CULLEN, J.M.; EDWARDS, J.F. et al. World Health Organization. Histological classification of tumors of the genital system of domestic animals. 2.ed. Washington: Armed Forces Institute of Pathology and American Registry of Pathology, 1998. 78p.

KRUPKE, D.M; BEGLEY, D.A.; SUNDBERG, J.P. et al. The Mouse tumor biology database. Nat. Rev. Cancer., v.8, p.459-465, 2008.

MACHADO, E.A.; LAIR, S.V.; GREGORY, R.S. Spontaneous fibrosarcoma in a thymustransplanted Nude mouse: Brief communication. J. Natl. Cancer Inst., v.58, p.1863-1865, 1977. 
MEUTEN, D.J.; EVERITT, J.; INSKEEP, W. et al. World Health Organization. Histological classification of tumors of the urinary system of domestic animals. 2.ed. Washington: Armed Forces Institute of Pathology and American Registry of Pathology, 2004. 70p.

MISDORP, W.; ELSE, R.W.; HELLMÉN, E. et al. World Health Organization. Histological classification of mammary tumors of the dog and cat. 2.ed. Washington: Armed Forces Institute of Pathology and American Registry of Pathology, 1999. 58p.

NÄF, D.; KRUPKE, D.M.; SUNDBERG, J.P. et al. The mouse tumor biology database: a public resource for cancer genetics and pathology of the mouse. Cancer Res., v.62, p.1235-1240, 2002.

NIELSEN, S.W. Diseases of the skin. In: BENIRSCHKE, K.; GARNER, F.M.; JONES, T.C. Pathology of Laboratory Animals. New York: Springer-Verlag, 1978. p.581-618.

NIELSEN, L.L.; DISCAFANI, C.M.; GURNANI, M. et al. Histopathology of salivary and mammary gland tumors in transgenic mice expressing a human Ha-ras oncogene. Cancer Res., v.51, p.3762-3767, 1991.

PHILlIPS, R.J.; HULSE, E.V. Two extragonadal teratomas in a mouse, with discussion of possible histogenesis. J. Comp. Pathol., v.92, p.273-284, 1982.

PREJEAN, J.D.; PECKHAM, J.C.; CASEY, A.E. et al. Spontaneous tumors in SpragueDawley rats and Swiss mice. Cancer Res., v.33, p.2768-2773, 1973.

RABSTEIN, L.S.; PETERS, R.L. Tumors of the kidneys, synovia, exocrine pancreas, and nasal cavity in BALB/cf/Cd Mice. J. Natl. Cancer Inst., v.51, p.999-1006, 1973.
ROWLLAT, C.; CHESTEERMAN, F.C.; SHERIFF, M.U. Lifespan, age changes and tumor incidence in an aging C57BL mouse colony. Lab. Anim., v.10, p.419-442, 1976.

SLAYTER, M.V.; BOOSINGER, T.R.; POOL, R.R. et al. World Health Organization. Histological classification of bone and joint tumors of domestic animals. 2.ed. Washington: Armed Forces Institute of Pathology and American Registry of Pathology, 1994. 50p.

STAATS, J. Standardized Nomenclature for inbred strains of mice: eight listing. Cancer Res., v.45, p.945-977, 1985.

TSUBURA, A.; YOSHIZAWA, K.; UEHARA, $\mathrm{N}$. et al. Multistep mouse mammary tumorigenesis through preneoplasia to neoplasia and acquisition of metastatic potencial. Med. Mol. Morphol., v.40, p.9-17, 2007.

THE JACKSON LABORATORY. The mouse tumor biology database. EUA, 2009. Disponível em <http://tumor.informatics.jax.org/ >. Acessado em: 19 jun. 2009

VALLI, V.E.; JACOBS, R.M.; PARODI, A.L. et al. World Health Organization. Histological classification of hematopoietic tumors of domestic animals. 2.ed. Washington: Armed Forces Institute of Pathology and American Registry of Pathology, 2002. 189p.

WADSWORTH, P.F. Tumours of the bone in C57BL/10J mice. Lab. Anim., v.23, p.324-327, 1989.

WARD, J.M.; GOODMAN, D.G.; SQUIRE, R.A. et al. Neoplastic and nonneoplastic lesions in aging $(\mathrm{C} 57 \mathrm{BL} / 6 \mathrm{~N} \times \mathrm{C} 3 \mathrm{H} / \mathrm{HeN}) \mathrm{F} 1(\mathrm{~B} 6 \mathrm{C} 3 \mathrm{~F} 1)$ mice. J. Natl. Cancer Inst., v.63, p.849-854, 1979. 